\title{
A Lamellar Ceria Structure with Encapsulated Platinum Nanoparticles
}

\author{
Angelo C. Mak, Changlin Yu, Jimmy C. Yu $(\bowtie)$, Zhendong Zhang, and Chunman Ho \\ Department of Chemistry, The Center of Novel Functional Molecules, and Environmental Science Programme, The Chinese University \\ of Hong Kong, Shatin, New Territories, Hong Kong, China \\ Received: 11 April 2008 / Revised: 17 June 2008 / Accepted: 28 October 2008 \\ CTsinghua Press and Springer-Verlag 2008. This article is published with open access at Springerlink.com
}

\begin{abstract}
A novel lamellar feather-like $\mathrm{CeO}_{2}$ structure has been fabricated by using a triblock copolymer as the structuredirecting agent. This material was characterized in detail by X-ray diffraction, scanning electron microscopy, transmission electron microscopy, X-ray photoelectron spectroscopy, and BET surface area measurements. Compared with conventional spherical shaped ceria prepared by ammonia gelation, the ceria feathers have superior ability to support nanosized platinum particles due to their special structure. The "skeletons" of ceria feathers can serve as an ideal host matrix to anchor the platinum particles. Furthermore, the inter-crossing pattern of the "skeletons" also acts as a partition to separate platinum particles, allowing the Pt nanoparticles (average diameter $\sim 6 \mathrm{~nm}$ ) to be highly dispersed in the structure. The $\mathrm{Pt} /$ feather-like $\mathrm{CeO}_{2}$ catalyst exhibits high activity in the water gas shift reaction.
\end{abstract}

\section{KEYWORDS}

Ceria, nanostructure, platinum, nanoparticles, surfactant-controlled synthesis, water gas shift reaction

\section{Introduction}

Ceria materials have been extensively studied because of their unique properties, including high oxygen storage capacity and good ion conductivity. The non-toxic and inexpensive $\mathrm{CeO}_{2}$ is widely used in the water gas shift (WGS) reaction [1], $\mathrm{H}_{2} \mathrm{~S}$ removal [2], three-way catalytic (TWC) conversion [3], fuel cell electrodes [4], oxygen storage [5], and chemical-mechanical planarization [6].

Ceria with a small grain size and a high surface area is highly desirable [7]. Colloidal nanocrystals are usually obtained by controlled growth in solution, using surfactants as structure directing agents [8]. Such surfactant-assisted pathways allow easy control over the composition, size, shape, crystal structure, and surface properties of nanocrystals. Several solution phase synthetic strategies have been developed including hydrothermal, microemulsions, nonhydrolytic sol-gel, ammonia gelation, and polyol synthesis methods [9]. Conventional spherical ceria particles can be prepared by ammonia gelation [10]. More exotic morphologies of ceria have also been reported. These include flower-like spheres [11], nanotubes [12], tadpole shaped nanowires [13], spindles and rods [14], nanocubes and

Address correspondence to jimyu@cuhk.edu.hk 
nanopolyhedra [15].

Nanoarchitectures with voids and hollow channels are superior catalysts [16]. Such morphology enhances the access of reaction molecules to the nanocrystalline material, which is especially important in heterogeneous catalysis [17]. However, materials with hollow channels are usually prone to sintering and they collapse easily after calcination.

The incorporation of hollow channels into ceria offers an additional advantage in that it allows further functionalization with nanosized metal clusters [18]. For example, Pt-ceria materials have been developed as active and stable catalysts for the WGS reaction [19]. The key to successful metal encapsulation lies in the stability of the ceria substrate, the high dispersion of metal particles, and strong interactions between the (NM) and the support [7]. The impregnation method also plays a crucial role in the preparation of highly active ceria catalysts. Small and highly dispersed NM particles are often powerful catalysts $[1,3,18]$. Unfortunately, highly dispersed NM particles are usually prone to aggregate. The aggregation of metal particles often leads to unexpectedly large nanocrystals and this remains a major hurdle, limiting the application of $\mathrm{NM} / \mathrm{CeO}_{2}$ in industry. In view of this, it would be interesting to fabricate ceria structures with special channels where the metal clusters can be dispersed and anchored.

In this paper, we describe the first synthesis of a ceria sample containing a periodic array of ordered nanocrystals, comprising a feather-like morphology with open-ended channels. More importantly, when compared with conventional spherical shaped ceria prepared by ammonia gelation, this special morphology showed superior ability in confining nanocrystalline platinum particles.

\section{Experimental}

\subsection{Chemicals}

Triblock copolymer $\mathrm{HO}\left(\mathrm{CH}_{2} \mathrm{CH}_{2} \mathrm{O}\right)_{20}\left(\mathrm{CH}_{2} \mathrm{CH}(\mathrm{C}\right.$ $\left.\left.\mathrm{H}_{3}\right) \mathrm{O}\right)_{70}\left(\mathrm{CH}_{2} \mathrm{CH}_{2} \mathrm{O}\right)_{20} \mathrm{H}\left(\mathrm{EO}_{20} \mathrm{PO}_{70} \mathrm{EO}_{20}\right.$, Pluronic $\mathrm{P} 123, \mathrm{MW}=5800)$, and cerium chloride hydrate $\left(\mathrm{CeCl}_{3} \cdot 7 \mathrm{H}_{2} \mathrm{O}\right)$ were purchased from Aldrich and used as received without further purification.

\subsection{Preparation of feather-like $\mathrm{CeO}_{2}$}

In a typical synthesis of nanofeathers, $16 \mathrm{~mL}$ absolute ethanol was used to homogenize $0.75 \mathrm{~g}$ P123 and $12 \mathrm{~g}$ deionized water. $2.8 \mathrm{~g}$ cerium chloride hydrate was added to the resultant solution. The resulting mother sol was aged on a Petri dish at $80{ }^{\circ} \mathrm{C}$ for $2^{-}$ 4 days, and then calcined at $400{ }^{\circ} \mathrm{C}$ for $4 \mathrm{~h}$. Spherical ceria particles were also prepared by the traditional ammonia gelation method. Cerium chloride hydrate was dissolved in deionized water to give a colorless solution. Then ammonia (35\%) was added drop-wise to the resulting solution until no more precipitation was observed. The hydrated precipitate was washed, filtered, and dried at $80^{\circ} \mathrm{C}$. Finally, the purple solid was calcined at $400{ }^{\circ} \mathrm{C}$.

\subsection{Synthesis of $\mathrm{Pt} /$ feather-like $\mathrm{CeO}_{2}$ catalyst}

The encapsulation abilities of different ceria supports, including nanofeathers and traditional spheres were tested. In a typical sonication-assisted encapsulation process [17], the ceria supports were immersed in a bottle filled with a solution of $50 \mathrm{mg} \mathrm{PtCl}_{4}$ in 10 $\mathrm{mL}$ deionized water. After sonication for 5-15 min, the powders (nanofeathers and nanospheres) were centrifuged, and washed with ethanol and deionized water in order to remove the surface adsorbed precursors. Finally, the powders were dried at $100{ }^{\circ} \mathrm{C}$.

\subsection{Characterization}

The BET surface areas of the sample were obtained from $\mathrm{N}_{2}$ adsorption/desorption isotherms determined at liquid nitrogen temperature on an automatic analyzer (ASAP 2010). The samples were outgassed for $2 \mathrm{~h}$ under vacuum at $180{ }^{\circ} \mathrm{C}$ prior to adsorption. Powder X-ray diffraction (XRD) data were recorded using a Bruker D8 Advance X-ray diffractometer with $\mathrm{Cu} \mathrm{K} \alpha_{1}$ irradiation $(\lambda=1.5406$ $\AA)$. Low angle XRD spectra $\left(2 \theta=0.5^{\circ}-5^{\circ}\right)$ were obtained using small size slits $(0.1 \mathrm{~mm}, 0.1 \mathrm{~mm}$, and $0.2 \mathrm{~mm}$ ). Wide angle XRD patterns were collected with larger size slits $(0.6 \mathrm{~mm}, 0.6 \mathrm{~mm}$, and $1.0 \mathrm{~mm})$ to amplify the signal intensity. Scanning electron microscopy (SEM) was carried out on an LEO 1450VP scanning electron microscope. Nanobeam

\section{Springer}


diffraction pattern and conventional transmission electron microscopy (TEM) images were recorded on a CM1220 microscope. A trace amount of sample was suspended in ethanol, followed by sonication for $10 \mathrm{~min}$. Carbon-coated copper grids were used as the sample holders. High resolution transmission electron microscopy (HTEM) images were recorded on a Tecnai 20 microscope. The preparation of samples was the same as for conventional TEM, except the carbon-coated copper grids were dried overnight at $100{ }^{\circ} \mathrm{C}$ to remove any residual solvent. The oxidation states and chemical environment of the sample was determined by X-ray photoelectron spectroscopy (XPS) (PHI Quantum 2000 XPS System), taking the $\mathrm{C} 1 \mathrm{~s}$ peak at $284.8 \mathrm{eV}$ of the surface adventitious carbon as reference.

The final concentration of $\mathrm{Pt}$ in the $\mathrm{Pt} /$ feather-like $\mathrm{CeO}_{2}$ sample was about $1 \%$ as determined by X-ray fluorescence (XRF) (Magix 601).

\subsection{Measurement of catalytic activity}

The catalytic activity of $\mathrm{Pt} /$ feather-like $\mathrm{CeO}_{2}$ in the water gas shift reaction was measured. A $0.1 \mathrm{~g}$ sample was placed in a fixed bed quartz microreactor with an inner diameter of $5 \mathrm{~mm}$. The reactor was placed in a temperature controlled electrical furnace. The reactant mixture composed of $\mathrm{CO}, \mathrm{H}_{2} \mathrm{O}$, and $\mathrm{He}(\mathrm{CO} /$ $\mathrm{H}_{2} \mathrm{O} / \mathrm{He}$ molar ratio $=1: 3: 21$ ) was fed to the reactor at a flow rate of $200 \mathrm{~mL} / \mathrm{min}$. The gaseous product was analyzed by a Shimadzu GC14-C chromatograph equipped with a TCD (Carbosieve SII).

\section{Results and discussion}

\subsection{BET and XRD analysis}

Figure 1 shows nitrogen adsorption-desorption isotherms and pore size distribution plots for the calcined feather-like $\mathrm{CeO}_{2}$. For comparison, the BET data of a conventional ceria sample prepared by the traditional ammonia gelation method are also presented in Table 1. The feather-like $\mathrm{CeO}_{2}$ has much higher specific surface area and pore volume than that of the conventional $\mathrm{CeO}_{2}$. The pore diameter of the feather-like $\mathrm{CeO}_{2}$ is about $7.9 \mathrm{~nm}$. Figure 2(a) shows the low-angle XRD pattern of the as-prepared
$\mathrm{CeO}_{2}$ before calcination. Two peaks at $1.56^{\circ}$ and $3.18^{\circ}$ were observed. The peaks can be indexed to the planes (100) and (200), with d-spacing values of $56.4 \AA$ and $27.9 \AA$, respectively. This indicates that

Table 1 BET surface areas (SBET), pore volume, and pore size of the samples

\begin{tabular}{c|c|c|c}
\hline Catalyst & $\begin{array}{c}\mathrm{S}_{\text {BET }} \\
\left(\mathrm{m}^{2} / \mathrm{g}\right)^{a}\end{array}$ & $\begin{array}{c}\text { Pore volume } \\
\left(\mathrm{cm}^{3} / \mathrm{g}\right)^{b}\end{array}$ & $\begin{array}{c}\text { Average pore } \\
\text { diameter }(\mathrm{nm})^{\mathrm{c}}\end{array}$ \\
\hline Feather-like $\mathrm{CeO}_{2}$ & 162 & 0.28 & 7.9 \\
Conventional $\mathrm{CeO}_{2}$ & 90 & 0.08 & 3.7 \\
\hline
\end{tabular}

${ }^{\text {a }}$ Calculated from the linear portion of the BET plot.

${ }^{\mathrm{b}}$ Calculated by means of total amount of adsorbed gas at $P / P_{0}=$ 0.98 .

${ }^{c}$ Average pore diameter, estimated using the desorption branch of the isotherm and the Barrett-Joyner-Halenda formula.

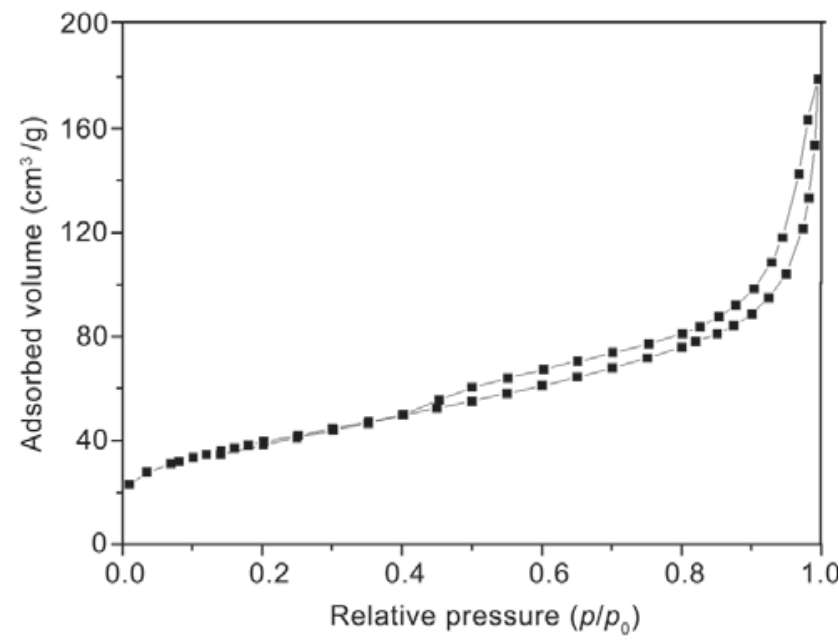

(a)

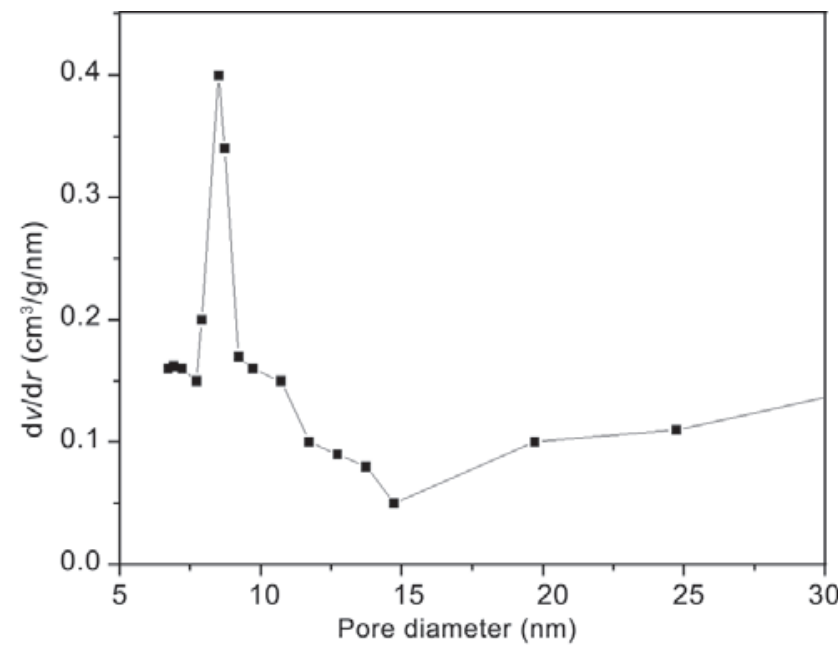

(b)

Figure 1 (a) $\mathrm{N}_{2}$-sorption isotherms and (b) the corresponding poresize distribution curves for Pt/feather-like $\mathrm{CeO}_{2}$ 


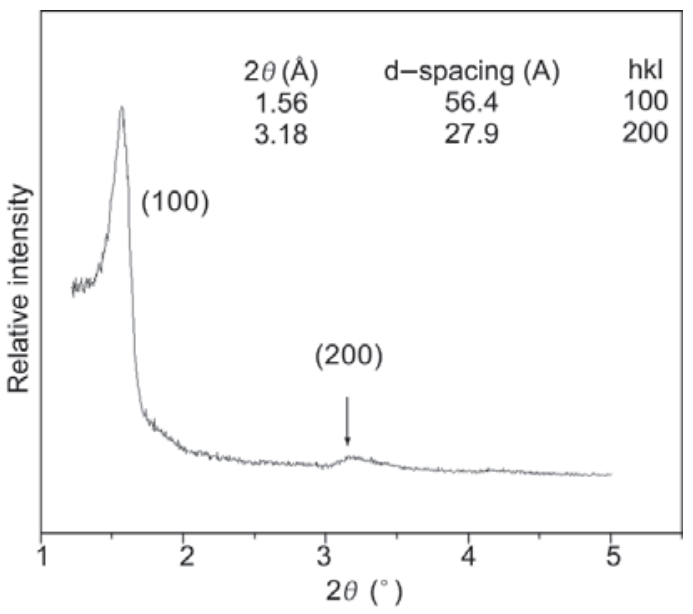

(a)

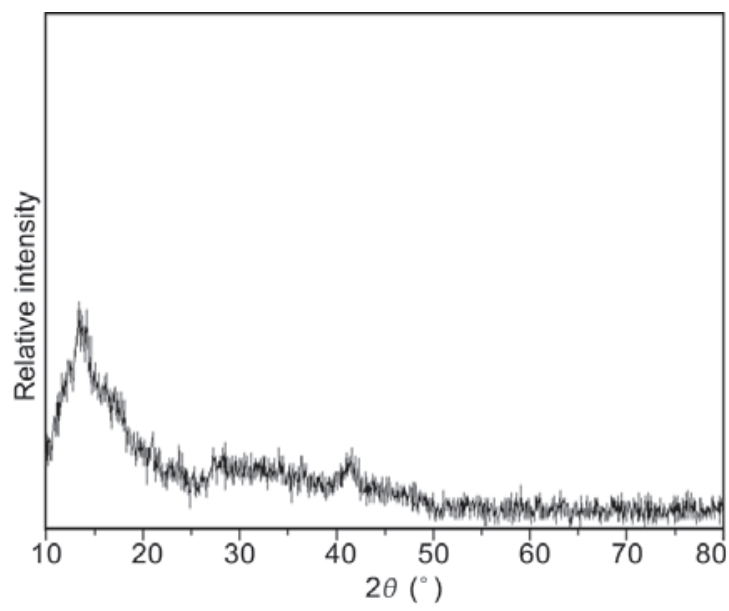

(b)

Figure 2 (a) Low-angle and (b) wide-angle XRD patterns of as-prepared $\mathrm{CeO}_{2}$ before calcination

the as-prepared sample has a typical lamellar mesostructure. The wide-angle XRD pattern (Fig. 2(b)) of the uncalcined sample shows no peaks characteristic of $\mathrm{CeO}_{2}$. Figures 3(a) and 3(b) show the low-angle and wide-angle XRD patterns of the $\mathrm{CeO}_{2}$ sample after calcination at $400{ }^{\circ} \mathrm{C}$. From Fig. 3(a), we can see that a very small (100) peak is present, which suggests that the calcined $\mathrm{CeO}_{2}$ retains a lamellar meso-structure. The wide-angle XRD pattern in Fig. 3(b) reveals that the calcined sample has a cubic fluorite structure as in the bulk $\mathrm{CeO}_{2}$ (JCPDS\# 34-0394). The average crystal size is only $4.8 \mathrm{~nm}$, as calculated by the
Scherrer equation from the full width half maximum of the (111) peak. The major peaks in the wide-angle XRD pattern are sharp and well-resolved, suggesting a well-defined crystalline nanostructure.

\subsection{SEM and TEM analysis}

The topography and morphology of the calcined ceria were analyzed by SEM. The SEM image (Fig. 4) shows a large quantity of feather-like rods with typical lengths of the order of several hundreds of nanometers. The morphology of the feather-like rods is very regular.

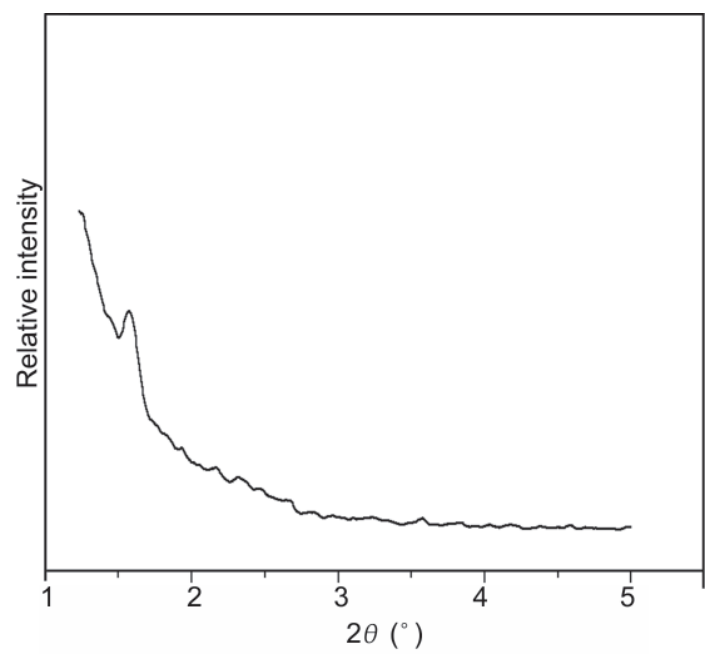

(a)

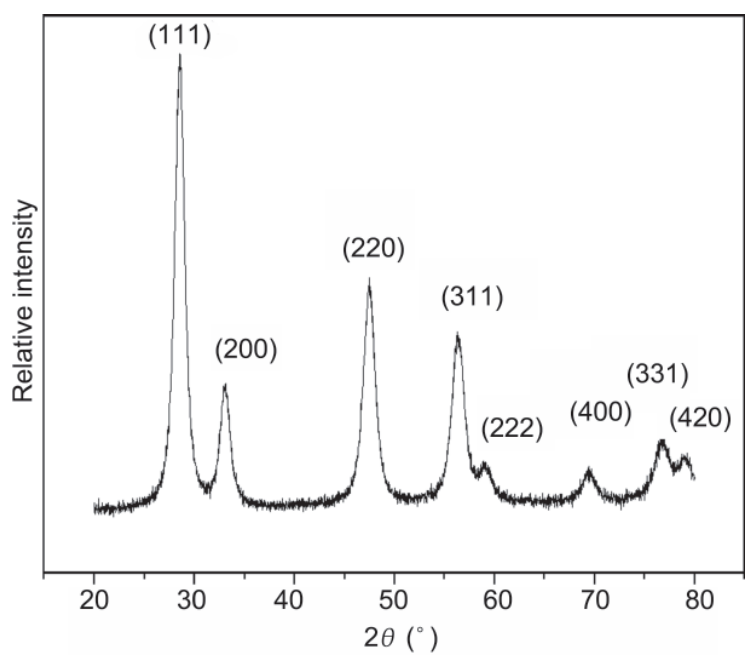

(b)

Figure 3 (a) Low-angle and (b) wide-angle XRD patterns of as-prepared $\mathrm{CeO}_{2}$ after calcination 




Figure 4 SEM micrograph of the calcined $\mathrm{CeO}_{2}$ sample

To further investigate the morphology of the feather-like rods, a low-magnification transmission electron microscopy (TEM) image was obtained. Figure 5 shows a clear image of the new featherlike morphology of the ceria. More interestingly, the feather motif shows an array of skeletons, branching and crossing each other in a very uniform pattern. Figure 6(a) further reveals that the nanofeathers are composed of strip-like structures originating from the central region and extending to the edges. The parallel strips are oriented at an inclination angle of approximately $45^{\circ}$ to the skeleton of the nanofeathers.



Figure 5 TEM image of the typical calcined feather-like morphology

HTEM was used to examine the strip-like structures. Figures 6(b) and 6(c) reveal the detailed structures of the edge and the central region of a nanofeather. Figure 6(b) shows that the strips are

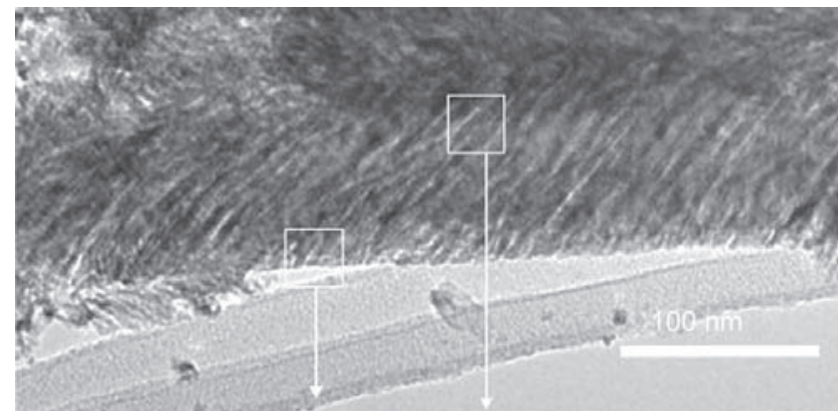

(a)

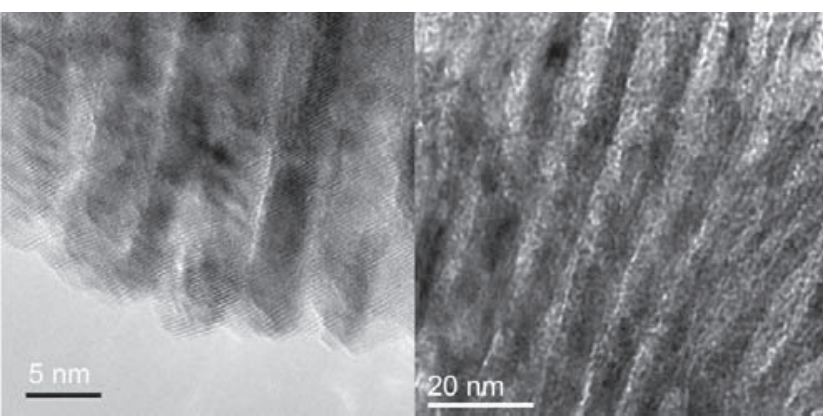

(b)

(c)

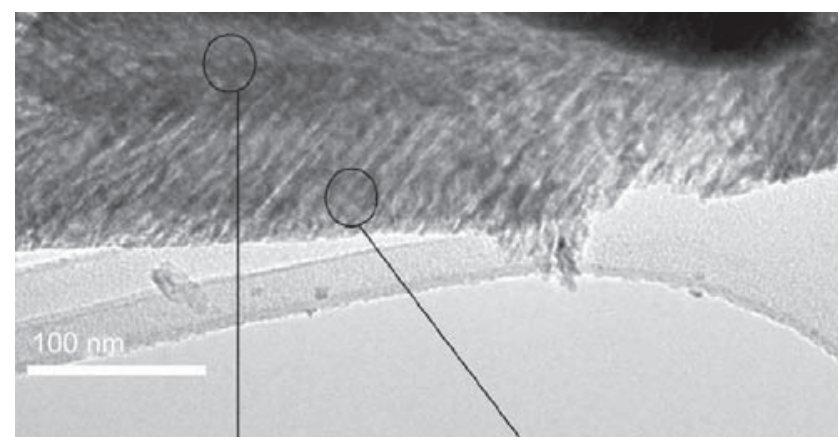

(d)

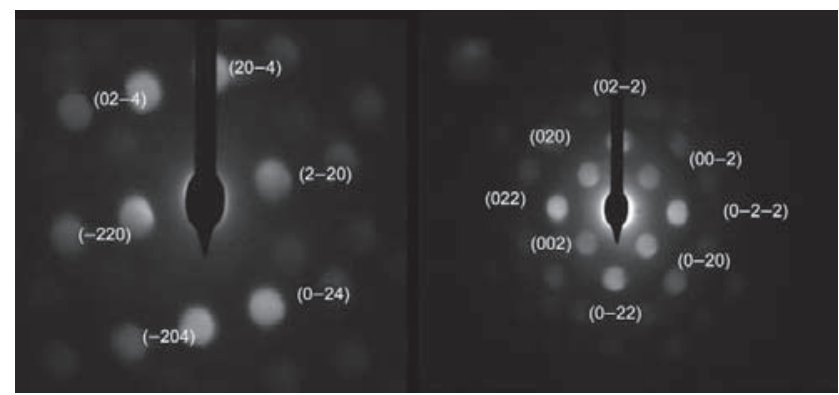

(e)

(f)

Figure 6 (a) Low magnification TEM image of a $\mathrm{CeO}_{2}$ feather nanostructure; (b), (c) high resolution TEM images of selected regions; (d) regions of a ceria feather selected for nanobeam diffraction analysis; (e), (f) electron diffraction images indexed according to a face-centered cubic lattice

nanosized with high aspect ratio, suggesting an array of lamellar layers. Figure 6(c) also presents strip-like structures that resemble lamellar layers. Both figures show similar strip-like structure on the nanoscale, 
confirming that these nanofeathers are structurally uniform.

To further study the nanocrystals, nanobeam diffraction was employed. Figure 6(d) displays a typical sample, in which feather-like nanoarchitecture can be observed. Diffraction patterns were recorded at the central region (Fig. 6(e)) and the edges (Fig. $6(\mathrm{f})$ ). Both figures show well defined discs, indicating the presence of crystal planes. These discs are indexed according to the face-centered cubic lattice, with Figs. 6(e) and 6(f) indexed with zone axes [211] and [110], respectively. The diffraction patterns also confirm crystallization along the (420), (220), and (222) planes. These crystallographic results are in good agreement with the XRD analysis.

It is well known that the activity of ceria can be greatly enhanced by the incorporation of a trace amount of NM. However, usually, these NM nanocrystals are very prone to aggregation, which decreases the activity of $\mathrm{NM} / \mathrm{CeO}_{2}$ catalysts. Therefore, we tested the encapsulation abilities of different ceria supports, including nanofeathers and traditional spheres.

In Figs. 7(a) and 7(b), it can be observed that the feather motif of the $\mathrm{Pt} /$ feather-like $\mathrm{CeO}_{2}$ remains well defined and intact even after sonication. More importantly, the "skeletons" of the feathers serve as an ideal host matrix for anchoring the platinum particles. The inter-crossing pattern of the "skeletons" also acts as a partition to separate platinum particles, allowing the particles (average diameter $\sim 6 \mathrm{~nm}$ ) to be highly dispersed in the entire nanofeather.
For comparison, Figures 8(a) and 8(b) shows the typical sphere shaped ceria nanospheres prepared by conventional ammonia gelation. The ceria nanospheres were treated with the same sonication-assisted encapsulation process, but almost no metal particles were identified. Most of the metal particles were apparently leached during the washing treatment procedure due to the weak encapsulation abilities of traditionally prepared ceria spheres.

From the above analysis, we can conclude that the advantages of ceria nanofeathers are: (1) their stability at high temperature and under sonication, (2) their skeletons act as anchors and partitions for $\mathrm{Pt}$ particles.

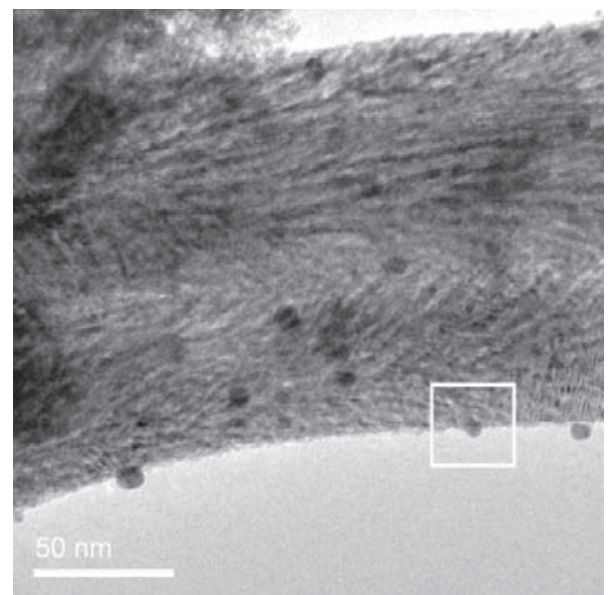

(a)

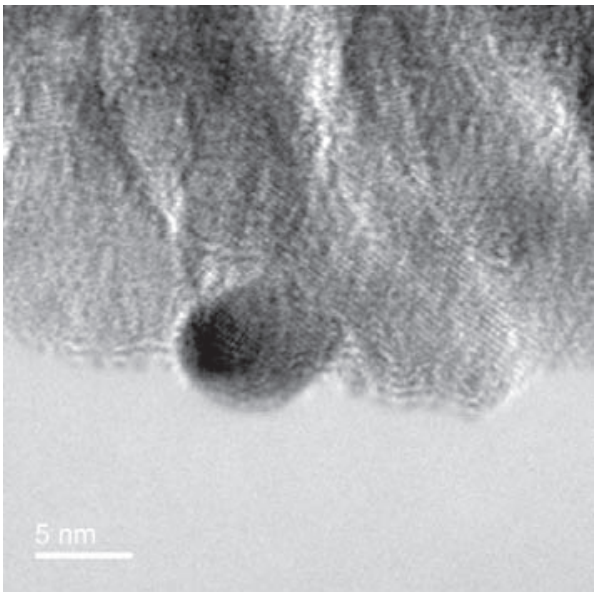

(b)
Figure 7 (a) TEM image of Pt/feather-like $\mathrm{CeO}_{2}$; (b) the HTEM image of the highlighted area

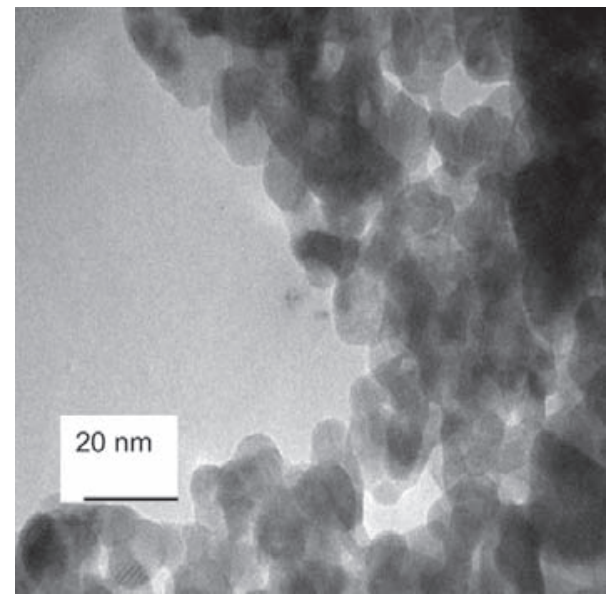

(a)

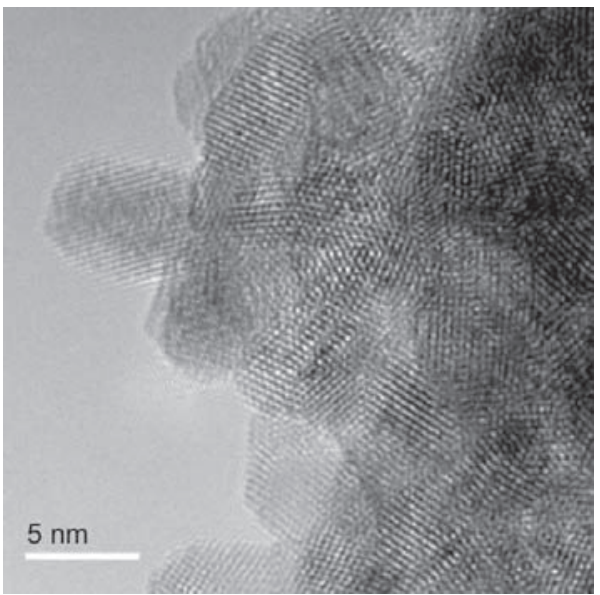

(b)
Figure 8 (a) TEM and (b) HTEM images of ceria nanocrystals prepared by conventional ammonia gelation 


\subsection{XPS analysis}

Typical XPS survey scans were conducted to detect the presence of $\mathrm{Ce}, \mathrm{O}$ and loaded Pt. As shown in Fig. 9, core levels of Ce $4 d, C e 3 d, O$ 1s, and C 1s could be identified. $\mathrm{Ce}$ and $\mathrm{O}$ originated from the feather support while carbon was used as a reference. Figure 9(b) gives the fine scan of Ce 3d. Due to very similar energies of the $4 \mathrm{f}$ and ligand orbital valence levels, the cerium species in $\mathrm{CeO}_{2}$ were capable of forming intermediates containing both $\mathrm{Ce}^{3+}$ and $\mathrm{Ce}^{4+}$, and therefore the XPS spectrum of ceria is actually a complex hybridization consisting of $\mathrm{Ce}^{3+}$ and $\mathrm{Ce}^{4+}$. The results were compared with previous investigations of ceria compounds [10, 14]. This comparison showed that the binding energies of $\mathrm{Ce}$ $3 \mathrm{~d}$ orbitals were in good agreement with literature values [7]. Peaks labeled $v_{0}, v_{2}$, and $v_{3}$ can be indexed to $\mathrm{Ce} 3 \mathrm{~d}_{5 / 2}$ photoemission lines of $\mathrm{Ce}^{4+}$, while $v_{1}$ can be attributed to special configurations in $\mathrm{Ce}_{2} \mathrm{O}_{3}$. Similarly, the corresponding $u_{1}$ to $u_{3}$ structures can be identified in the Ce $3 \mathrm{~d}_{3 / 2}$ photoemission lines, as shown in Fig. 9.

The curves fitting of the Pt $4 \mathrm{f}$ core-level spectrum (Fig. 9(c)) were performed by using two spin-orbit split $\mathrm{Pt} 4 \mathrm{f}_{7 / 2}$ and $\mathrm{Pt} 4 \mathrm{f}_{5 / 2}$ components. The one at lower binding energy corresponds to the $\mathrm{Pt} 4 \mathrm{f}_{7 / 2}$ level and the second one, at higher binding energy, corresponds to the $\mathrm{Pt} 4 \mathrm{f}_{5 / 2}$ level. The Pt $4 \mathrm{f}_{7 / 2}$ peak (about $70.5 \mathrm{eV}$ ) showed that Pt was mainly in the metallic state, consistent with a previous report [20]. The exact assignment of this peak is not easy, because the binding energy of core electrons is not only affected by the metal oxidation state but also by the ligand atoms to which they are coordinated. In the literature, authors frequently discovered that $\mathrm{Pt}^{2+}$ and $\mathrm{Pt}^{0}$ coexisted and attributed this phenomenon to incomplete reduction [10]. In this sample, the $\mathrm{Pt}$ peaks indicated $\mathrm{Pt}^{0}$ to be the main detectible $\mathrm{Pt}$ species. This suggests that most of the Pt cations, originating from the $\mathrm{PtCl}_{4}$ precursor, were reduced to metallic form after encapsulation. No obvious Pt peaks were found for the ceria nanospheres treated with the same sonication-assisted encapsulation process.

\subsection{Formation mechanism of nanofeather-like $\mathrm{CeO}_{2}$ and $\mathrm{Pt} /$ feather-like $\mathrm{CeO}_{2}$ catalyst}

A proposed mechanism for the formation of ceria nanofeathers is shown in Fig. 10. On the basis of our observations, a combination of self-assembly and junction formation was used to explain the growth of the robust feather-like nanostructure. The process started with a solution containing ethanol, water, P123, and cerium precursor. As a result of evaporation of the solvents, the concentration of surfactant exceeded the critical micellar concentration, forming a lamellar meso-structure. The low-angle XRD spectrum of the structure showed two peaks at $1.56^{\circ}$ and $3.18^{\circ}(2 \theta)$ (Fig. 2(a)). The peaks were indexed as the (100) and (200) planes with d-spacing values of $56.4 \AA$ and $27.9 \AA$, respectively. This is typical for a lamellar meso-structure. Calcination at $400{ }^{\circ} \mathrm{C}$ removed the surfactant. It is known that most lamellar mesostructures collapse without the

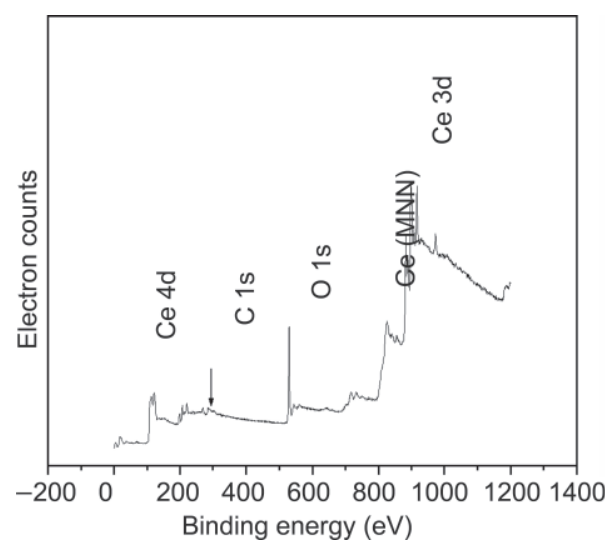

(a)

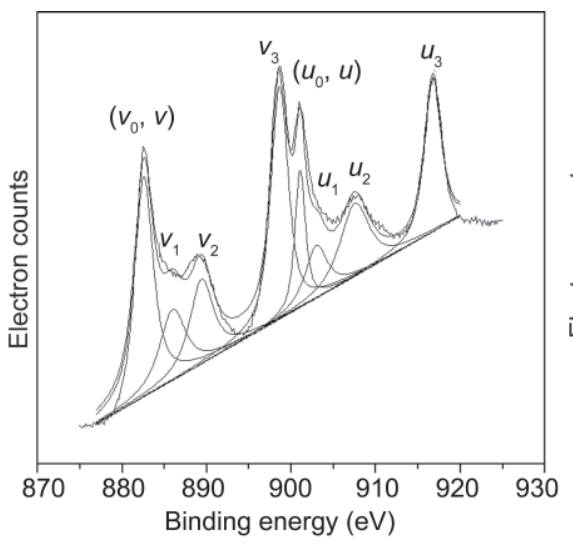

(b)

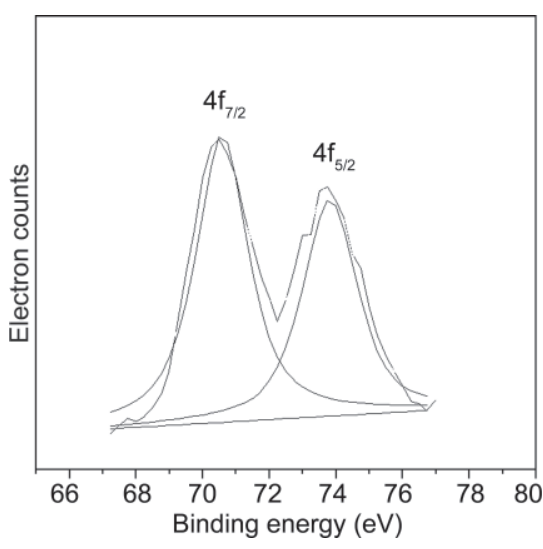

(c)

Figure 9 (a) XPS survey scan for Pt/feather-like $\mathrm{CeO}_{2}$; (b) XPS fine scan for Ce 3d; (c) XPS fine scan for Pt $4 f$ 



Figure 10 Schematic representation of the formation of feather-like $\mathrm{CeO}_{2}$ and Pt/feather-like $\mathrm{CeO}_{2}$

support of a surfactant. Interestingly, the calcined nanofeathers also showed an ordered feather pattern (Figs. 3(a) and 6). The intercrossing and branching of the nanofeathers probably originated from the fusion between neighboring lamellar layers. The resultant junctions provided support to the entire nanostructure even after the surfactant was removed. This two-step model not only accounts for the formation of the feather-like morphology, but also for its robustness.

As for the $\mathrm{Pt} /$ feather-like $\mathrm{CeO}_{2}$ sample, it was found from XPS analysis that most of the metal was reduced after encapsulation. The major reactions occurring when water is sonicated [ ())))] can be summarized by the following equation [18]:

$$
\mathrm{H}_{2} \mathrm{O} \stackrel{())))}{\longrightarrow} \mathrm{H} \cdot+\cdot \mathrm{OH}
$$

The highly reducing free radicals might further reduce cationic metal precursors to zero-valent states [21]:

$$
\begin{aligned}
& \mathrm{PtCl}_{4}+4 \mathrm{H} \cdot \longrightarrow \mathrm{Pt}^{0}+4 \mathrm{Cl}^{-}+4 \mathrm{H}^{+} \\
& n \mathrm{Pt}^{0} \longrightarrow \mathrm{Pt}_{n}
\end{aligned}
$$

\subsection{Catalytic activity tests}

The catalytic performance of the novel $\mathrm{Pt} /$ featherlike $\mathrm{CeO}_{2}$ catalyst for the water gas shift reaction was examined. For comparison, a sample prepared by simple impregnation of $1 \% \mathrm{Pt}$ onto $\mathrm{CeO}_{2}$ obtained by the traditional ammonia gelation method was also tested $\left(\mathrm{Pt} /\right.$ ordinary $\left.\mathrm{CeO}_{2}\right)$. The results are shown in Fig. 11. For the pure feather-like $\mathrm{CeO}_{2}$ sample, almost no $\mathrm{CO}$ conversion can be observed. The $\mathrm{Pt} /$ feather-

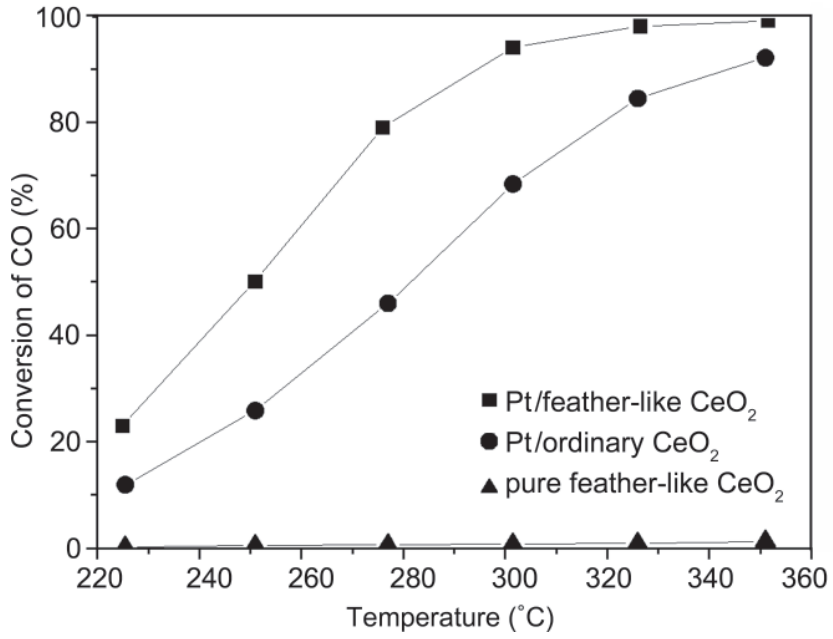

Figure 11 Activity of the samples in the water gas shift reaction

like $\mathrm{CeO}_{2}$ shows much higher activity than that of $\mathrm{Pt}$ / ordinary $\mathrm{CeO}_{2}$. At $225^{\circ} \mathrm{C}$, the $\mathrm{CO}$ conversion was $22 \%$. The CO conversion increased rapidly at higher temperatures, reaching virtually complete conversion at $330{ }^{\circ} \mathrm{C}$. The high activity of $\mathrm{Pt} /$ feather-like $\mathrm{CeO}_{2}$ can be attributed to the higher specific surface area and pore volume, which causes an increase in the contact boundary between Pt and the ceria support, thus promoting the catalytic activity.

\section{Conclusions}

In summary, we report the first preparation of a lamellar feather-like ceria structure by a surfactantassisted pathway. After thermal treatment at $400{ }^{\circ} \mathrm{C}$, the product is composed of an ordered array 
of skeletons, which intercross and branch to form a uniform feather pattern. Such a novel structure allows nanosized platinum catalysts to be firmly anchored. A high activity for the water gas shift reaction was observed with this novel catalyst.

\section{Acknowledgements}

The authors thank Dr. Yadong Bi for measuring the catalytic activities at Dalian Institute of Chemical Physics, the Chinese Academy of Sciences. This research was supported by a Strategic Investments Scheme administered by The Chinese University of Hong Kong.

\section{References}

[1] Fu, Q.; Saltsburg, H.; Flytzani-Stephanopoulos, M. Active nonmetallic Au and Pt species on ceria-based water-gas shift catalysts. Science 2003, 301, 935-938.

[2] Flytzani-Stephanopoulos, M.; Sakbodin, M.; Wang, Z. Regenerative adsorption and removal of $\mathrm{H}_{2} \mathrm{~S}$ from hot fuel gas streams by rare earth oxides. Science 2006, 312, 1508-1510.

[3] Carrettin, S.; Concepción, P.; Corma, A.; Nieto, J. M. L.; Puntes, V. F. Nanocrystalline $\mathrm{CeO}_{2}$ increases the activity of $\mathrm{Au}$ for $\mathrm{CO}$ oxidation by two orders of magnitude. Angew. Chem. Int. Ed. 2004, 43, 2538-2540.

[4] Park, S. D.; Vohs, J. M.; Gorte, R. J. Direct oxidation of hydrocarbons in a solid-oxide fuel cell. Nature 2000, 404, 265-267.

[5] Rothenberg, G.; de Graaf, E. A.; Bliek, A. Solvent-free synthesis of rechargeable solid oxygen reservoirs for clean hydrogen oxidation. Angew. Chem. Int. Ed. 2003, 42, 3366-3368.

[6] Feng, X. D.; Sayle, D. C.; Wang, Z. L.; Paras, M. S.;Santora, B.; Sutorik, A. C.; Sayle T. X. T.; Yang, Y.; Ding, Y.; Wang, X. D.; Her, Y. S. Converting ceria polyhedral nanoparticles into single-crystal nanospheres. Science 2006, 312, 1504-1508.

[7] Trovarelli, A. Catalysis by Ceria and Related Materials; Imperial College Press: London, 2002.

[8] Yin, Y.; Alivisatos, A. P. Colloidal nanocrystal synthesis and the organic-inorganic interface. Nature 2005, 437, 664-670.

[9] Cushing, B, L.; Kolesnichenko, V. L.; O'Connor, C. J. Recent advances in the liquid-phase syntheses of inorganic nanoparticles. Chem Rev. 2004, 104, 3893-3946.

[10] Ho, C. M.; Yu, J. C.; Wang, X. C.; Lai, S. Y.; Qiu, Y. F. Meso- and macro-porous $\mathrm{Pd} / \mathrm{Ce}_{x} \mathrm{Zr}_{1-x} \mathrm{O}_{2}$ as novel oxidation catalysts. J. Mater. Chem. 2005, 15, 2193-2201.

[11] Sun, C. W.; Sun, J; Xiao, G. L.; Zhang, H. R.; Qiu, X. P.; Li, H, Chen, L. Q. Mesoscale organization of nearly monodisperse flower-like ceria microspheres. J. Phys. Chem. B 2006, 110, 13445-13452.

[12] Han, W. Q.; Wu, L. J.; Zhu, Y. M. Formation and oxidation state of $\mathrm{CeO}_{2-x}$ nanotubes. J. Am. Chem. Soc. 2005, 127, 12814-12815.

[13] Yu, T. Y.; Joo, J.; Park, Y. I.; Hyeon, T. Large-scale nonhydrolytic sol-gel synthesis of uniform-sized ceria nanocrystals with spherical, wire, and tadpole shapes. Angew. Chem. Int. Ed. 2005, 44, 7411-7414.

[14] Ho, C. M.; Yu, J. C.; Kwong, T.; Mak, A. C.; Lai, S. Y. Morphology-controllable synthesis of mesoporous $\mathrm{CeO}_{2}$ nano-and microstructures. Chem. Mater. 2005, 17, 4514 -4522 .

[15] Mai, H. X.; Sun, L. D.; Zhang, Y. W.; Si, R.; Feng, W.; Zhang, H. P.; Liu, H. C.; Yan, C. H. Shape-selective synthesis and oxygen storage behavior of ceria nanopolyhedra, nanorods, and nanocubes. J. Phys. Chem. B 2005, 109, 24380-24385.

[16] Rolison, D. R. Catalytic nanoarchitectures - the importance of nothing and the unimportance of periodicity. Science 2003, 299, 1698-1701.

[17] Yu, J. C. ; Wang, X. C. ; Fu, X. Z. Pore-wall chemistry and photocatalytic activity of mesoporous titania molecular sieve films. Chem. Mater. 2004, 16, 1523-1530.

[18] Yu, J. C.; Wang, X. C.; Wu, L.; Ho, W. K.; Zhang, L. Z.; Zhou, G.T. Sono- and photochemical routes for the formation of highly dispersed gold nanoclusters in mesoporous titania films. Adv. Funct. Mater. 2004,14, 1178-1183.

[19] Deng, W.; Flytzani-Stephanopoulos, M. On the issue of the deactivation of Au-ceria and Pt-ceria water-gas shift catalysts in practical fuel-cell applications. Angew. Chem. Int. Ed. 2006, 45, 2285-2289.

[20] Ruiz-Martı́nez, J. ; Coloma, F. ; Sepúlveda-Escribano, A.; Anderson, J. A.; Rodríguez-Reinoso, F. Effect of tin content and reduction temperature on the catalytic behaviour of $\mathrm{PtSn} / \mathrm{TiO}_{2}$ catalysts in the vapour-phase hydrogenation of crotonaldehyde. Catal. Today 2008, 133, 35-41

[21] Leighton, T. G. The Acoustic Bubble; Academic Press: London, 1994. 